\section{RESEARCH ARTICLE \\ 10.1029/2018JC014526 \\ Subtropical Mode Water and Permanent Pycnocline Properties in the World Ocean}

Key Points:

- In each subtropical basin, the stratification pattern of a mode water pycnostad overlying a permanent pycnocline exists continuously throughout the gyre

- The pycnocline has a double-bowl pattern with two deep centers colocated with thick mode waters and shallower in the center of the gyre

- The North Atlantic subtropical permanent pycnocline and mode waters are much deeper, thicker, and less stratified than those in other gyres

Supporting Information:

- Supporting Information S1

- Figure S1

- Figure S2

- Figure S3

Correspondence to:

C. Feucher,

feucher@ualberta.ca

Citation:

Feucher, C., Maze, G., \&

Mercier, H. (2019). Subtropical mode

water and permanent pycnocline

properties in the World Ocean.

Journal of Geophysical Research:

Oceans, 124, 1139-1154.

https://doi.org/10.1029/2018JC014526

Received 7 SEP 2018

Accepted 29 JAN 2019

Accepted article online 4 FEB 2019

Published online 20 FEB 2019

\author{
Charlène Feucher ${ }^{1}$ iD , Guillaume Maze ${ }^{2}$ iD), and Herlé Mercier ${ }^{3}$ (D) \\ ${ }^{1}$ Department of Earth and Atmospheric Sciences, University of Alberta, Edmonton, Alberta, Canada, ${ }^{2}$ Ifremer, \\ University of Brest, CNRS, IRD, Laboratoire d'Océanographie Physique et Spatiale (LOPS), IUEM, Brest, France, \\ ${ }^{3}$ University of Brest, CNRS, IRD, Ifremer, Laboratoire d'Océanographie Physique et Spatiale (LOPS), IUEM, Brest, France
}

\begin{abstract}
A global reference state of the subtropical mode water and permanent pycnocline properties for the 2000-2015 period is presented. The climatology is obtained from a pattern recognition algorithm applied to stratification profiles from the Argo global array. The stratification features are identified as permanent upper ocean pycnostad and pycnocline even when the seasonal pycnocline is developed. The climatology shows that both Northern Hemisphere subtropical gyres have a qualitatively very similar stratification structure. The permanent pycnoclines in the North Atlantic and North Pacific show two deep centers colocated with thick subtropical and subpolar mode waters. These centers coincide with modes in the density and stratification space. These deep pycnocline centers are separated by a region with a shallower and thinner permanent pycnocline that is located downstream of Western Boundary Current Extensions and upstream of Eastern Subtropical Fronts. This feature creates a remarkable double-bowl pattern at the basin scale. In the subtropical gyres of the South Atlantic and South Pacific Oceans, the mode water and permanent pycnocline structures are characterized by two modes in the density and stratification space that, unlike in the Northern Hemisphere, do not necessarily correspond to deep and thick permanent pycnocline regions. In the subtropical gyre of the South Indian Ocean, a single mode is found to correspond to a single center in the western part of the gyre. This study also shows that away from these deep centers where the pycnocline depth almost follows isopycnals, the permanent pycnocline experiences significant thermohaline gradients that are not density compensated.
\end{abstract}

Plain Language Summary The vertical structure of the ocean is of great importance to understand the impact of climate changes on the global ocean because a larger density differences (i.e., increased stratification) between the upper and the deeper ocean can prevent anthropogenic excess of heat, and carbon, from reaching the abyssal ocean. Using data from autonomous Argo floats that sample the ocean properties (e.g., temperature and salinity) from the surface down to 2,000 $\mathrm{m}$, we describe the vertical structure of the ocean's surface layers at midlatitudes, where heat is mostly stored in the upper 1,000 m. This new study shows for the first time (i) a strong dependence of the ocean properties of the surface layer with the ocean properties of the transition layer with the abyss and (ii) that this transition layer exhibits rapid changes in temperature and density when rising to the surface as well as in the center of the each oceans. These new results are a significant refinement to the classic depiction of the midlatitude ocean as a simple bowl of warm water separated from the abyss by a layer of constant density and thus provide an accurate benchmark for climate models to detect long-term changes in the ocean vertical structure.

\section{Introduction}

Since the 1970s, global warming of the ocean has been observed and this warming is not homogeneously distributed (Cheng et al., 2017; Roemmich et al., 2015). Over the global ocean, the warming is enhanced along western boundary currents and the tropical/subtropical band (Levitus et al., 2012; Wu et al., 2012). Over depth, beyond the sea surface warming, the largest heat gain has occurred in the midthermocline layer, that is, the upper $700 \mathrm{~m}$ (Häkkinen et al., 2016; Wang et al., 2018). These changes in the upper ocean stratification have been shown to drive ocean oxygen and nutrient reductions in the thermoclines of the Northern Hemisphere (Helm et al., 2011; Talley et al., 2016) and will possibly drive changes of key ocean dynamical components in the future (e.g., reduce the Atlantic Overturning Circulation strength;
(C)2019. American Geophysical Union. All Rights Reserved. 
Carton et al., 2014). It is thus of paramount importance to our understanding of climate change impacts onto the physical ocean and its biogeochemistry to be able to diagnose ocean stratification changes.

The increase in upper ocean heat content has an impact on the subtropical gyre stratification and the subtropical mode water properties (Häkkinen et al., 2015; Kelly \& Dong, 2013; Kelly et al., 2014; Williams et al., 2015). Ocean heat content increase has led to an increase in the volume of subtropical mode waters (Häkkinen et al., 2015). This volume change is mostly due to the deepening of isopycnals that contributed to the fixed depth heat content changes (Häkkinen et al., 2016). However, a robust anticorrelation between ocean heat content and North Atlantic subtropical mode water volume in the western part of the gyre has been shown before (Dong \& Kelly, 2004; Dong et al., 2007; Kelly \& Dong, 2013; Kwon, 2003). Such discrepancies can arise from different definitions of the subtropical mode waters mainly from one using isopycnal or isothermal ranges versus one based on a layer of minimum stratification (Forget et al., 2011). Defining mode waters as a pycnostad, that is, a stratification minimum, allows for a proper long-term variability tracking of their properties. For instance, using a vertical thermal gradient minimum method, Sugimoto et al. (2017) have recently shown that the North Pacific and North Atlantic subtropical mode waters have warmed over the past six decades twice faster than the ocean sea surface. Similarly, diagnosing the equatorial Pacific thermocline as a stratification maximum, Yang and Wang (2009) have shown that the thermocline low-frequency variability is not always consistent with the one inferred using vertical migration of an isothermal surface. Overall, in the context of long-term ocean changes, these studies have highlighted that one should not infer mode water and pycnocline vertical migrations from those of isopycnals but instead from the change in their stratification. The motivation of the present study is thus to provide a-still missing-global reference state of the subtropical stratification features based on vertical gradients and that would take advantage of the unprecedented Argo data global coverage (Riser et al., 2016).

Indeed, 17 years have passed since the distributions for the subtropical mode waters was broadly shown by Talley (1999) and Hanawa and Talley (2001). During this time, Argo floats have been deployed globally and they provide us with new perspectives on subtropical mode waters and the stratification beyond. The advent of the global Argo observational array has been used by Speer and Forget (2013) to characterize subtropical mode waters distribution in an ocean state estimate, but their approach remained a synthesis and focused on the North Atlantic subtropical mode water. A more systematic approach based on a thermal stratification identification criteria for which parameters are adapted to each mode waters was used by Tsubouchi et al. (2016) to objectively compare subtropical mode waters and investigate the dominant factors influencing their vertical structure and formation mechanisms. Their study suggest the important role played by the large-scale circulation, most notably the overturning component, to explain differences between mode water properties. However, their mode water definition was solely based on temperature and did not take advantage of Argo salinity data.

Moreover, no global description nor intercomparison of the subtropical permanent pycnoclines have been done yet. This may be surprising because the structure of the subtropical pycnocline is a corner stone of physical oceanography studies. Mapping of potential vorticity on isopycnal surfaces have been done as early as the 1980s by McDowell et al. (1982) for the North Atlantic and Keffer (1985) for the global ocean. This has contributed to the fundamental adiabatic wind-driven ventilated thermocline theory (Huang, 1990; Luyten et al., 1983; Talley, 1985), which was consequently improved and further developed to take into account more complex processes like eddy mixing (e.g., Cessi \& Fantini, 2004; Radko \& Marshall, 2004), the surface mixed layer (e.g., Williams, 1991), and to reconcile effects of diabatic with adiabatic processes (e.g., Cessi, 2007; Vallis, 2006). Pedlosky (2006) provides a historical, and personal, account of these theories.

To address the current lack of an objective, observation-based, global description of the pycnocline as a permanent stratification maximum (to be contrasted with isopycnal depths), an algorithm was recently presented out in Feucher (2016). She used a simple diagnostic method that allows for a simultaneous and coherent estimate of the surface mode waters and the underlying permanent pycnocline properties. Applied to the North Atlantic by Feucher et al. (2016), this methodology has shown that the permanent pycnocline cannot be approximated by a single isopycnal surface. This work highlighted the need for a subtropical pycnocline diagnostic based on a stratification criteria rather than on isopycnal depth to monitor the variability of its properties, as highlighted previously.

In this paper, we aim to provide a modern climatology of the global subtropical stratification, not limited to mode waters but extending down to the permanent pycnocline. This can be seen as a characterization of the 
(a)
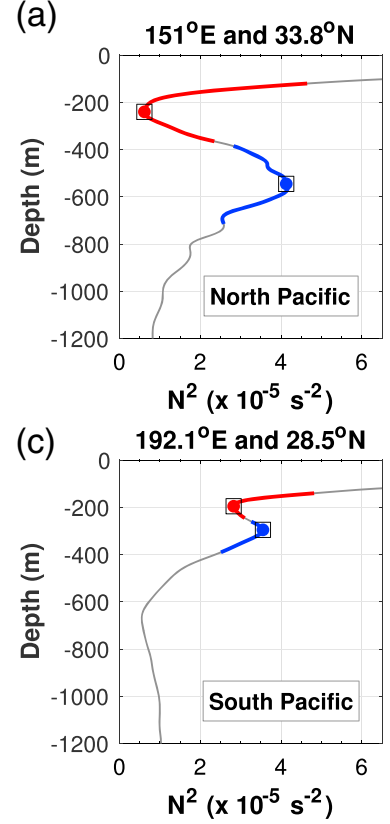

(b)
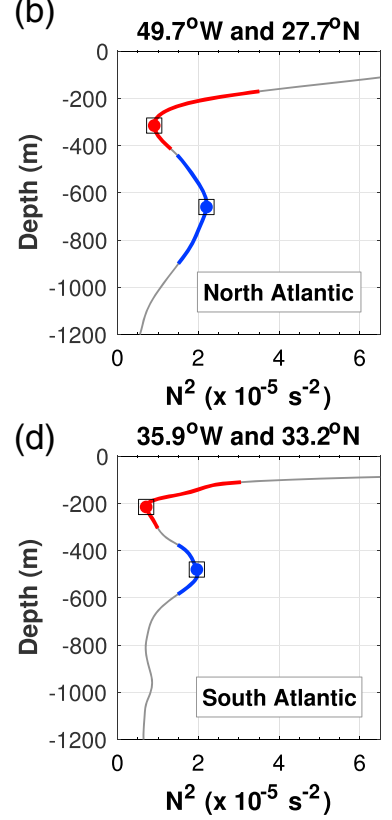

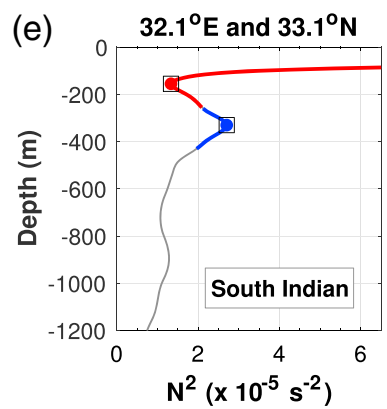

Figure 1. Samples of mode water and permanent pycnocline diagnostics issued from the Objective Algorithm for the Characterization of the Permanent Pycnocline algorithm ran on selected Argo stratification profiles. Profiles are located in (a) North Pacific subtropical gyre (WMO 2902946, cycle 68), (b) North Atlantic subtropical gyre (WMO 4900788, cycle 68), (c) South Pacific subtropical gyre (WMO 5902182, cycle 22), (d) South Atlantic subtropical gyre (WMO 3900442, cycle 22), and (e) South Indian subtropical gyre (WMO 1901429, cycle 2). The gray curves are smoothed $N^{2}$ profiles, the red, respectively blue, parts of the profiles highlight the mode water and permanent pycnocline layers, respectively (dots indicate the core depth of each layers). WMO = World Meteorological Organization.

warm water sphere at midlatitudes. Note that we excluded the mixed layer in our product because accurate climatologies are already available (e.g., de Boyer Montégut et al., 2004, and subsequent updates). Beyond the details of the climatology that will be presented hereafter, the reader may simply want to directly jump to the combined representation of our results shown Figure 6. This schematic is both an refinement and update to the well-known Hanawa \& Talley's (2001) Plate 5.4.3 focusing on subtropical mode waters and a new global description of the permanent pycnocline properties.

The paper is organized as follows: in section 2 we present the data set and methodology, and in section 3 we present and describe the 2000-2015 Argo climatology of subtropical mode waters and permanent pycnoclines depth, thickness, and thermohaline properties. The climatology is finally discussed section 4 .

\section{Data and Method}

We used data from the Argo observational array that provides global temperature and salinity profiles from the surface down to 2,000 $\mathrm{m}$ in real time since 2007 (Riser et al., 2016). Argo data were downloaded from the FTP server of the French Global Data Assembly Center Coriolis in February 2016 (Argo, 2016). We selected profiles in the global ocean with Quality Control flags on pressure, temperature, and salinity set to 1, 2, 5, or 8, which are considered as good data (see reference Table 2 in Carval et al., 2013). We obtained a collection of 1,226,177 profiles spanning the period of January 2000 to December 2015.

To estimate properties of the permanent pycnocline and mode water in subtropical gyres, we implemented the Objective Algorithm for the Characterization of the Permanent Pycnocline (OAC-P) developed by Feucher (2016). This method was applied to the North Atlantic by Feucher et al. (2016). OAC-P recognizes the mode water core as a stratification, that is, Brunt-Väisälä frequency $\left(N^{2}\right)$, minimum that is temporarily trapped below the seasonal pycnocline in summer. The permanent pycnocline is recognized as the stratification maximum localized below that mode water core. For consistency with the bibliography we computed the surface mode water thickness from the depths of the $\pm 1^{\circ} \mathrm{C}$ isotherms around the local potential temperature at the stratification minimum depth (e.g., Tsubouchi et al., 2016). On the other hand, a more complex 
model (based on half Gaussians) is fitted to stratification profiles in order to determine the thickness of the permanent pycnocline (see for details Feucher et al., 2016).

Compared to the North Atlantic, we had to modify two parameters in the use of the OAC-P algorithm for its appropriate application to the Pacific, South Atlantic, and South Indian Oceans: the smoothing length scale applied to $N^{2}$ profiles was reduced to $20 \mathrm{~m}$ (from $50 \mathrm{~m}$ ) and the maximum expected depth of the surface mode water reduced to $300 \mathrm{~m}$ (from $500 \mathrm{~m}$ ). This was required because the permanent pycnocline and mode water are deeper and thicker in the North Atlantic than in all the other gyres, as will be shown in the next section. Note that compared to Feucher et al. (2016), here we present results for the North Atlantic that are based on one additional year of data.

Figure 1 shows results from the OAC-P algorithm for typical subtropical stratification profiles located in each of the five gyres. Superimposed on stratification profiles are the mode water and the permanent pycnocline core depth and thickness. Whatever the profile's location, OAC-P performs as expected and is able to recognize patterns associated with each mode water and permanent pycnocline that are qualitatively similar and yet differ much quantitatively.

Last, following Feucher et al. (2016), the collection of profiles with OAC-P diagnostics are furthermore filtered using an unsupervised classification method (Gaussian Mixture Model) in order to isolate subtropical profiles from outliers and from profiles in regions not of interest here (the subpolar gyre and tropical and equatorial regions). The data selected for subtropical gyres are finally mapped on a regular $1^{\circ} \times 1^{\circ}$ grid using a simple Gaussian-distance weighted mean. Supporting information Figure S1b shows the number of OAC-P profile diagnostics used in the mapping.

The data set of the 2000-2015 Argo climatological maps of the World Ocean subtropical mode waters and permanent pycnoclines properties is made publicly available at http://doi.org/10.17882/56503 (Feucher et al., 2018).

\section{Results}

We found that on global average, the mode water layer is about $250 \mathrm{~m}$ deep and $160 \mathrm{~m}$ thick, and the permanent pycnocline layer is $410 \mathrm{~m}$ deep and $230 \mathrm{~m}$ thick (Figure 2). The upper part of the permanent pycnocline is half thinner $(80 \mathrm{~m})$ than the lower part $(150 \mathrm{~m})$, which leads to an average form factor of 50\% (Figure S2). However, these global means hide large regional differences and coherent regional patterns. To emphasize these patterns and ease the intercomparison of the five subtropical gyres, the color scale for each of the maps was normalized basin wide (see caption Figure 2 for details). Basin-averaged values are indicated on each of the figures.

We also note that mode waters are best identified using the diagnosed thickness (Figure 2b), or equivalently, potential vorticity and $N^{2}$ (Figures 3a and 3c). Using the mode water thermohaline properties, we were able to identify these mode waters consistently with well-known characteristics of subtropical mode waters of types I, II, III, and IV (Hanawa \& Talley, 2001; Tsubouchi et al., 2016). Thus, in the following, to distinguish mode water flavors, we will follow the nomenclature from Hanawa and Talley (2001). Unfortunately, there is no classification for the different flavors of regional subtropical permanent pycnoclines.

\subsection{Western Subtropical Stratification}

The western part of all the subtropical gyres is marked by a thick mode water and a deep permanent pycnocline forming a bowl-like pattern centered approximately around: $65^{\circ} \mathrm{W}, 34^{\circ} \mathrm{N}$ in the North Atlantic (NATL), $140^{\circ} \mathrm{E}, 31^{\circ} \mathrm{N}$ in the North Pacific (NPAC), $180^{\circ} \mathrm{E}, 42^{\circ} \mathrm{S}$ in the South Pacific (SPAC), $40^{\circ} \mathrm{W}, 33^{\circ} \mathrm{S}$ in the South Atlantic (SATL), and $45^{\circ} \mathrm{E}, 37^{\circ} \mathrm{S}$ in the South Indian (SIO; Figure 2). All thick western mode waters and deep permanent pycnoclines are localized on the equatorward flank of their respective Western Boundary Current (or Sub-Antarctic Front in the case of the SPAC; see Figure 6). In the NPAC, NATL, and SATL one may note a small difference between the position of the core center of the thickest mode water and that of the deepest permanent pycnocline. But this detail cannot be asserted more reliably given the resolution of the data set.

Thus, it is not surprising to find that a similar feature to all the subtropical gyres is that in the western part, the diagnosed mode water is that of type I. The western mode water of type I stands as a regional thickness maxima, except in the South Pacific where (although the mode water of type I is appropriately identified by 

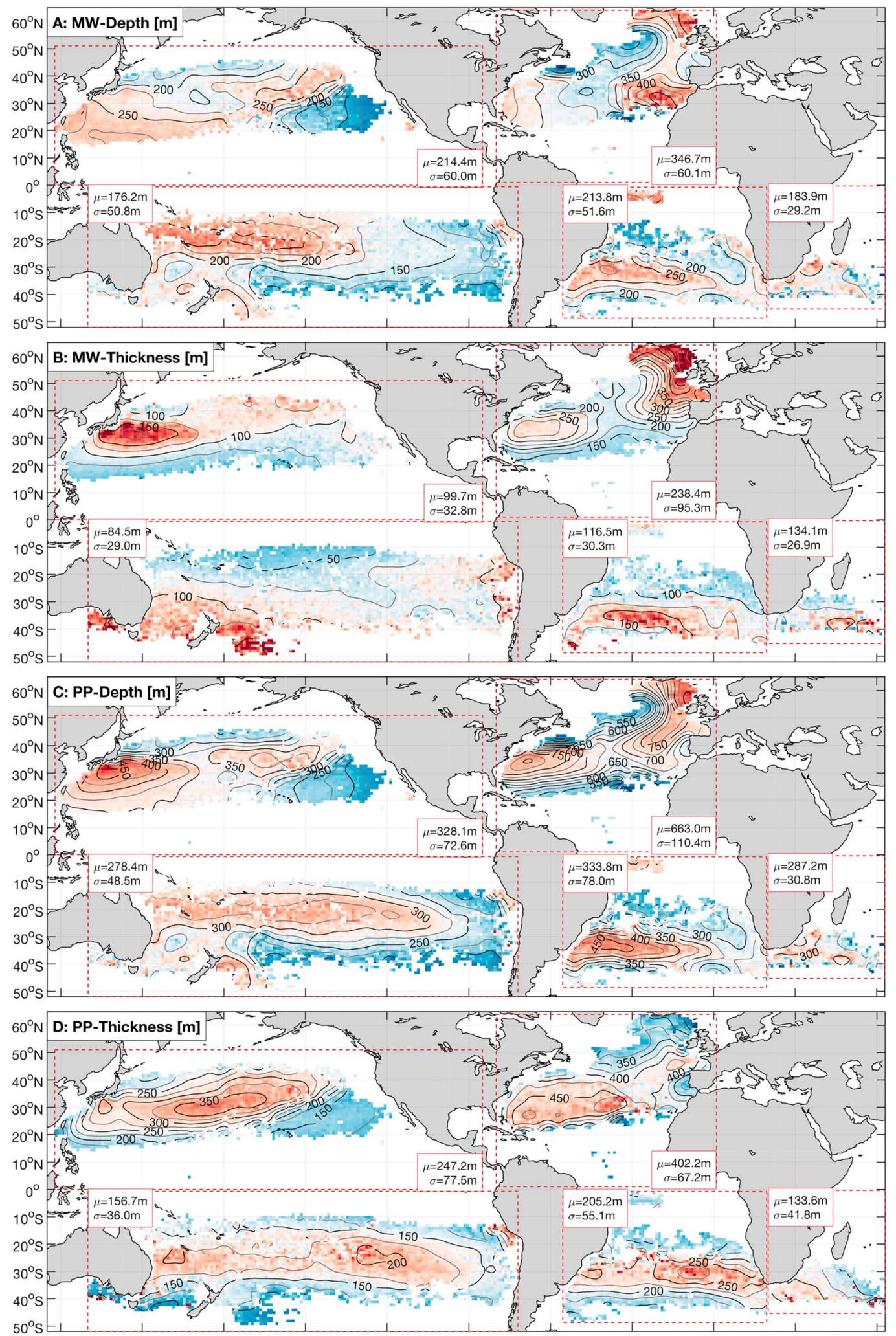

Figure 2. The 2000-2015 Argo climatology of subtropical mode water and permanent pycnocline depth and thickness (in meters): (a) mode water depth, (b) mode water thickness, (c) permanent pycnocline depth, (d) permanent pycnocline thickness. For all plots, contours are every $25 \mathrm{~m}$, labeled every $50 \mathrm{~m}$. To allow for an easier comparison of patterns, the color scale has been normalized for each basin separately (the mean $\mu$ and standard deviation $\sigma$ are given in the respective insets). Red (blue) areas thus correspond to higher (lower) values than the basin mean, and the color saturation is reached at $3 \sigma . \mathrm{MW}=$ mode water; $\mathrm{PP}=$ permanent pycnocline. 

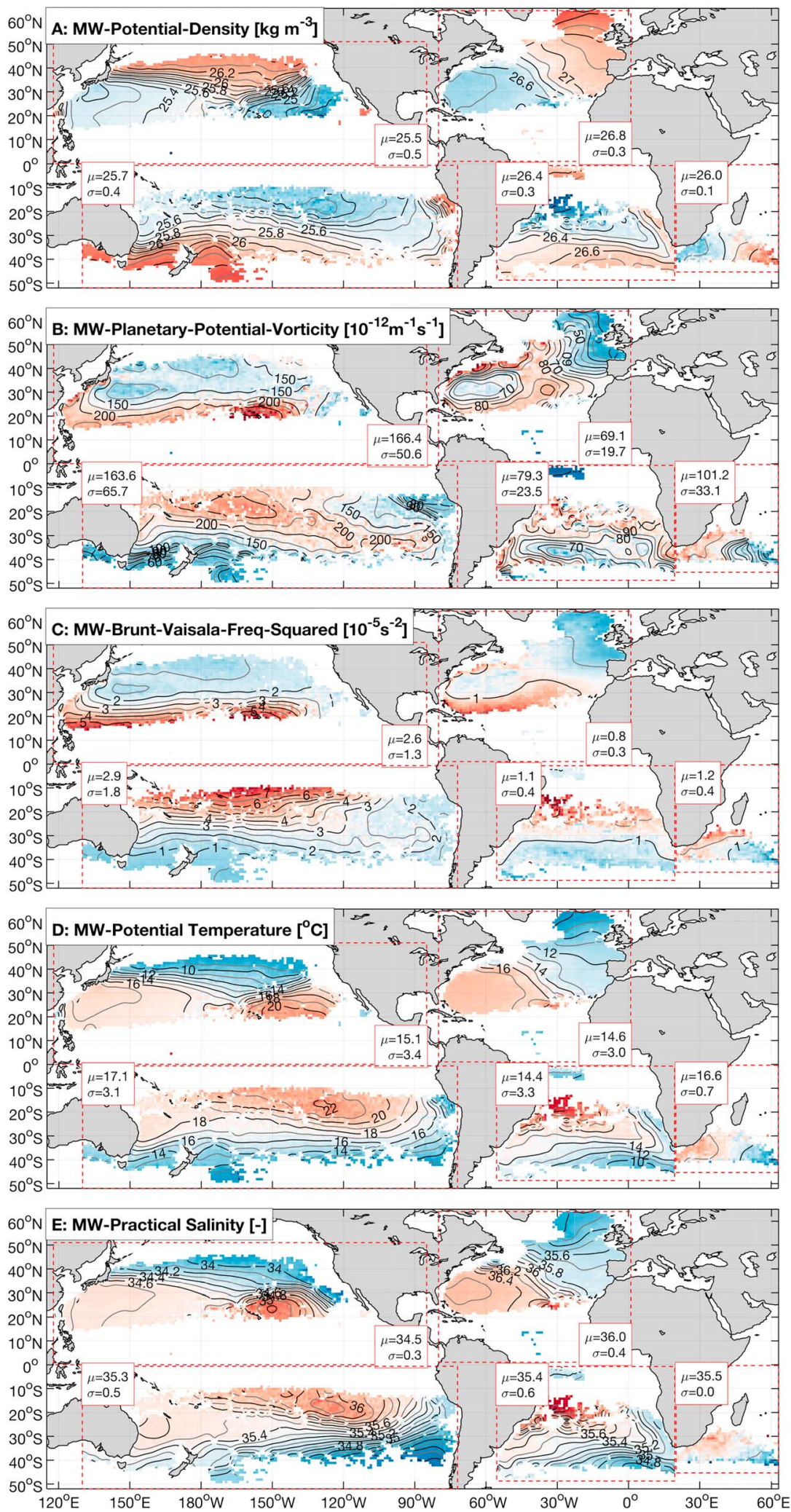

Figure 3. The 2000-2015 Argo climatology of subtropical mode water thermohaline properties. (a) Potential density (contours every $0.1 \mathrm{~kg} / \mathrm{m}^{3}$ ), (b) potential vorticity (contours every $5 \times 10^{-12} \mathrm{~m}^{-1} \cdot \mathrm{s}^{-1}$ in the North Atlantic, $25 \times 10^{-12} \mathrm{~m}^{-1} \cdot \mathrm{s}^{-1}$ elsewhere), (c) squared Brunt-Väisälä frequency (contours every $0.5 \times 10^{-5} \mathrm{~s}^{-2}$ ), (d) potential temperature (contours every $1^{\circ} \mathrm{C}$ ), and (e) practical salinity (contours every 0.1 ). See Figure 2 caption for the color scaling. $\mathrm{MW}=$ mode water. 
its thermohaline properties; see Figure 3) the western mode water thickness extrema is associated with the mode water of type III localized further south, beyond the Tasmanian Front (see dark red region in Figure 6).

The western mode water and permanent pycnocline structures in the NATL and NPAC furthermore share several detailed similarities. For instance, the depth of the mode water of type I does not show a similar pattern to that of the permanent pycnocline. Instead of a bowl shape, it rather deepens from the Western Boundary Current (the Gulf Stream and Kuroshio; see Figure 6) westward and equatorward (Figure 2a).

With regard to permanent pycnocline thicknesses, another similarity between the NATL and NPAC is that the upper permanent pycnocline thickness (Figure S2a) show a very similar pattern to that of the mode water of type I, which indicates a counterintuitive correlation between mode water and permanent pycnocline thickness. Figures 2d and S2c moreover show that deep western permanent pycnocline centers are also thickness local extrema symmetric with regard to the core permanent pycnocline depth. This means that the upper and lower layers of the permanent pycnocline are of about the same thickness (the upper permanent pycnocline accounts for $30 \%$ to $50 \%$ of the total permanent pycnocline thickness).

Last, in the SATL, another mode water was identified in the western equatorward region of the gyre. This mode water is associated with the subtropical high-salinity water (see Figure 3e) and corresponds to the Subtropical Underwater (Tsuchiya et al., 1994). Note that although Hanawa and Talley (2001) indicated that this flavor of mode water (type IV) exists in all basins, we identified it clearly only in the SATL.

\subsection{Eastern Subtropical Stratification}

The eastern part of the subtropical gyre has specific properties for each basins. We found that only the NPAC and NATL eastern mode water and permanent pycnocline are qualitatively similar. The eastern part of these gyres is marked by a thick mode water and a deep permanent pycnocline forming another bowl-like pattern (Figure 2). These eastern bowls are centered around $15^{\circ} \mathrm{W}, 46^{\circ} \mathrm{N}$ in the NATL and $160^{\circ} \mathrm{W}, 35^{\circ} \mathrm{N}$ in the NPAC. The thick mode water is that of type III. In both basins, these mode waters are a variety of central mode waters (using the NPAC terminology Oka \& Qiu, 2012), a more stratified version of mode waters formed near the Sub-Arctic Front spreading southwestward through the subtropical gyre. In the NATL it also clearly encompasses the Subpolar Mode Water of the Iceland Basin. Contrasting with the western part, the mode water core depth of the eastern part of the gyre shows a bowl-like pattern similar to the permanent pycnocline one.

In the SPAC, the eastern mode water is that of type II, the largest of its kind worldwide. One has to look at the $N^{2}$ stratification at the depth of the mode water (Figure 3c) to determine its westward extension to about $130^{\circ} \mathrm{W}\left(N^{2}<4 \times 10^{-5} \mathrm{~s}^{-2}\right)$. The permanent pycnocline depth does show a bowl-like pattern, but only along the meridional axis (e.g., along $110^{\circ} \mathrm{W}$ ). Along the zonal axis, the permanent pycnocline deepens westward from $90^{\circ} \mathrm{W}$ to $140^{\circ} \mathrm{W}$. Further west, a deepening to $170^{\circ} \mathrm{W}$ is possible but robust.

In the SATL and SIO, there is no clear signature of an eastern mode water in thickness. In the SIO this is because OAC-P diagnostic data in the eastern part were too scattered to be shown and described confidently. In the SATL the region with density lower than $26.5 \mathrm{~kg} / \mathrm{m}^{3}$ emanating from GoodHope (Figure 3a) toward the northwest is reminiscent of the mode water of type II. However, dominated by intermittent Agulhas ring water, it does not stand as a mode water thickness regional extrema.

In the NPAC, the mode water of type II Hautala and Roemmich (1998) is also captured in the southeastern part of the gyre where it is associated with a large meridional potential temperature gradient from 16 to $20{ }^{\circ} \mathrm{C}$ (Figure 4d). But it does not corresponds to a thickness extrema. Last, one should also note that we did not identify the mode water of type II in the NATL, or “Madeira Mode Water" (Siedler et al., 1987).

With regard to thicknesses, the upper permanent pycnocline thickness of the eastern part of the NPAC gyre is clearly smaller $(<50 \mathrm{~m})$ than in the western part $(>100 \mathrm{~m}$; Figure S2a). We observe the same contrast in the NATL. In the SPAC, the upper permanent pycnocline thickness shows a clear regional maximum $\left(>100 \mathrm{~m}\right.$ ) around $110^{\circ} \mathrm{W}, 25^{\circ} \mathrm{S}$.

\subsection{Subtropical Structures in the Density and Stratification Space}

To put into perspective these regional patterns, Figure 5 shows scatter plots of $\sigma_{0}$ versus $N^{2}$ at the depth of the mode water (red dots) and at the depth of the permanent pycnocline (blue dots) for each of the gyres. Contours are the probability density function for each of the layers. 

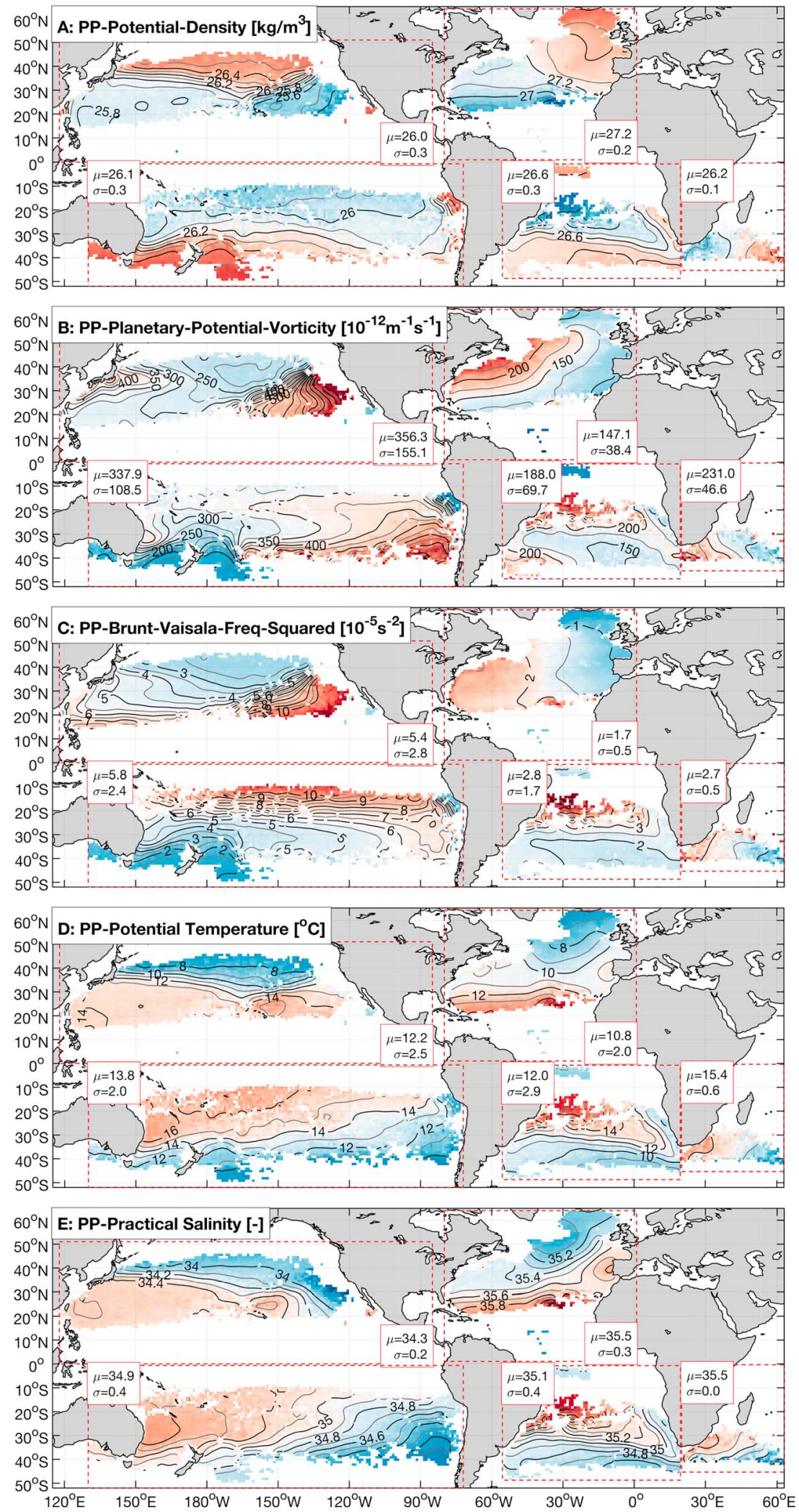

Figure 4. The 2000-2015 Argo climatology of subtropical permanent pycnocline thermohaline properties. (a) potential density (contours every $0.1 \mathrm{~kg} / \mathrm{m}^{3}$ ), (b) potential vorticity (contours every $25 \times 10^{-12} \mathrm{~m}^{-1} \cdot \mathrm{s}^{-1}$ ), (c) squared Brunt-Väisälä frequency (contours every $0.5 \times 10^{-5} \mathrm{~s}^{-2}$ ), (d) potential temperature (contours every $1^{\circ} \mathrm{C}$ ), and (c) practical salinity (contours every 0.1 ). See Figure 2 caption for the color scaling. $\mathrm{PP}=$ permanent pycnocline. 

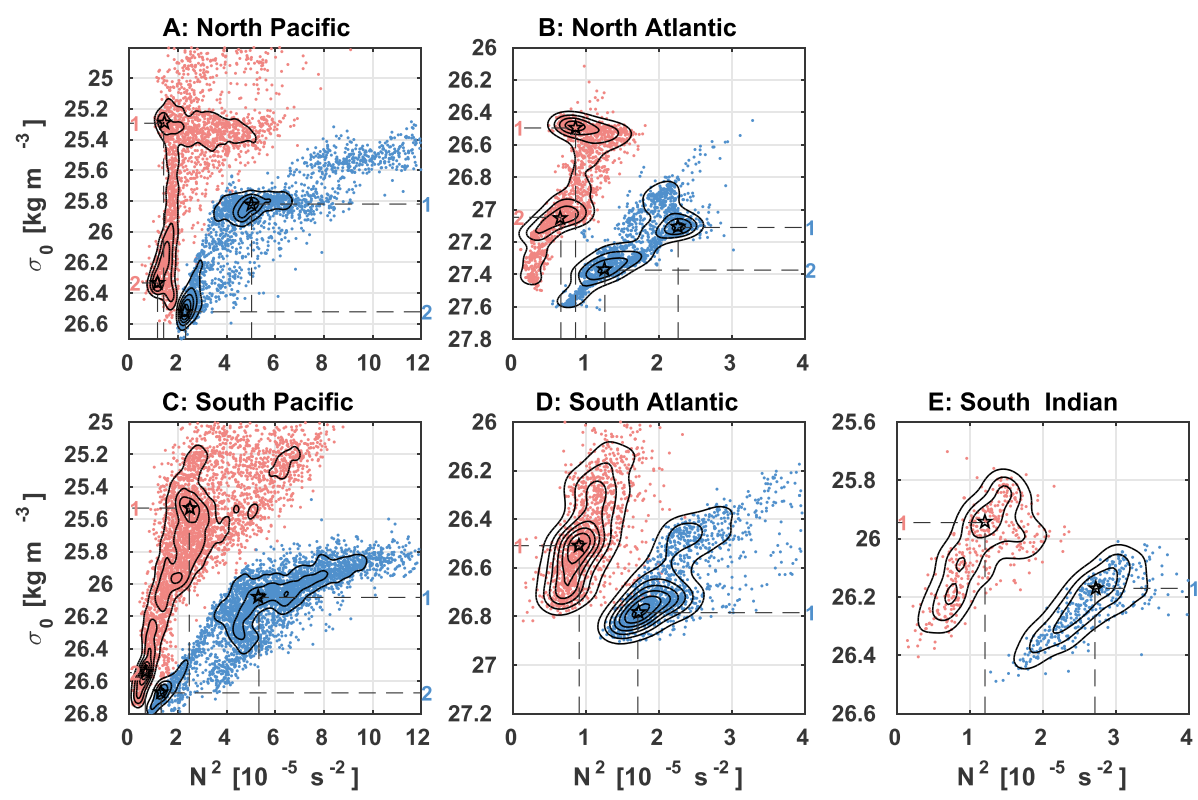

Figure 5. Scatter plots of $\sigma_{0}$ versus $N^{2}$ at the depth of the mode water (red dots) and permanent pycnocline (blue dots) surfaces for (a) the North Pacific subtropical gyre, (b) the North Atlantic subtropical gyre, (c) the South Pacific subtropical gyre, (d) South Atlantic subtropical gyre, and (e) the South Indian subtropical gyre. Black contours indicate the observed probability density function for each surfaces. The horizontal and vertical dashed lines indicate the center of each modes identified in this plan. These scatter plots are based on maps of Objective Algorithm for the Characterization of the Permanent Pycnocline $\sigma_{0}$ and $N^{2}$ diagnostics shown Figures $3 \mathrm{a} / 3 \mathrm{c}$ and $4 \mathrm{a} / 4 \mathrm{c}$.

These probability density functions clearly reveal at least one mode in all basins and a second mode in the NPAC, NATL, and SPAC. The mean mode water and permanent pycnocline properties for each of these modes are given Table 1.

For each basins and each layers, it is found that the denser the mode, the less stratified it is. These modes furthermore correspond to the particular eastern or western patterns described in the previous section. In all basins but the SPAC, the lighter modes correspond to the western patterns. In the NATL and NPAC, the denser modes correspond to the eastern stratification patterns, while in the SPAC they correspond to the western patterns. For the NATL and NPAC, the thickest mode water and the deepest permanent pycnocline regions coincide very well with the isopycnal modes identified Figures 5a/5b.

In the SPAC, the scatter plot also suggests the existence of another small mode water mode centered around $26.0 \mathrm{~kg} / \mathrm{m}^{3}$. This mode contains the denser version of the mode water of type I of the SPAC (Tsubouchi et al., 2007). Note that the full range of mode water with density between 25.5 and $26.0 \mathrm{~kg} / \mathrm{m}^{3}$ extends from the Australian East coast to the center of the SPAC basin near $150^{\circ} \mathrm{W}$ (Figure 3a). The underlying permanent pycnocline has density ranging from 26 to $26.3 \mathrm{~kg} / \mathrm{m}^{3}$.

In the SATL, one can also distinguish two smaller mode water modes around 26.3 and $26.7 \mathrm{~kg} / \mathrm{m}^{3}$. They correspond to the eastern mode water of type II, a light flavor of the SATL Central Water, and to the light component of Subantarctic Mode Water (SAMW; Donners et al., 2005; Provost et al., 1999). These mode water modes have their permanent pycnocline counterparts with densities of $26.5 \mathrm{~kg} / \mathrm{m}^{3}$ and larger than $26.8 \mathrm{~kg} / \mathrm{m}^{3}$, respectively.

The Northeast Atlantic stands out as having the densest and less stratified permanent pycnocline, while the western NPAC mode is the lightest and the eastern SPAC is the most stratified. The North Atlantic also hosts the densest mode water. With regard to all the modes identified in Figure 5, the North Atlantic subtropical stratifications is clearly an outlier compared to the other basins (see Table 1 for numerical values).

Another remarkable feature of each of these scatter plots is that modes are not strictly isolated; that is, data exist continuously between them. The probability density function contours for the permanent pycnocline delineate a monotonic, yet nonlinear, relationship whereby the permanent pycnocline density decreases with its stratification amplitude. In other word, the less stratified is the permanent pycnocline, the denser 
Table 1

Properties of the Mode Water and Permanent Pycnocline Layers Identified by OAC-P in Each of the Five Subtropical Gyres

\begin{tabular}{|c|c|c|c|c|c|c|c|}
\hline & & $\begin{array}{l}\text { Depth } \\
\text { (m) }\end{array}$ & $\begin{array}{c}\text { Thickness } \\
\text { (m) }\end{array}$ & $\begin{array}{c}\sigma_{0} \\
\left(\mathrm{~kg} / \mathrm{m}^{3}\right)\end{array}$ & $\begin{array}{c}N^{2} \\
\left(\times 10^{-5} \mathrm{~s}^{-2}\right)\end{array}$ & $\begin{array}{c}\theta \\
\left({ }^{\circ} \mathrm{C}\right)\end{array}$ & $\begin{array}{l}S \\
(-)\end{array}$ \\
\hline \multicolumn{8}{|l|}{ Mode waters } \\
\hline \multicolumn{8}{|c|}{ North Pacific subtropical gyre } \\
\hline Light mode & MW-I & $229(122-277)$ & $176(93-212)$ & $25.29(25.2-25.4)$ & $1.4(1.2-1.6)$ & $16.9(13.2-17.4)$ & $34.9(33.8-34.9)$ \\
\hline Dense mode & MW-III & $183(98-247)$ & $111(48-147)$ & $26.34(26.3-26.4)$ & $1.2(0.9-1.4)$ & $9.0(7.7-11.5)$ & $34.2(33.9-34.6)$ \\
\hline \multicolumn{8}{|c|}{ North Atlantic subtropical gyre } \\
\hline Light mode & MW-I & $344(215-440)$ & $262(111-339)$ & $26.49(26.4-26.6)$ & $0.9(0.6-1.1)$ & $17.6(16.7-18.2)$ & $36.7(36.5-36.9)$ \\
\hline Dense mode & $\begin{array}{l}\text { MW-III/ } \\
\text { SPMW }\end{array}$ & $347(192-482)$ & $243(139-376)$ & $27.05(27.0-27.1)$ & $0.7(0.4-0.9)$ & $12.0(9.3-13.5)$ & $35.8(35.1-36.1)$ \\
\hline \multicolumn{8}{|c|}{ South Pacific subtropical gyre } \\
\hline Light mode & MW-II & $150(99-227)$ & $84(46-122)$ & $25.53(25.5-25.6)$ & $2.5(2.2-2.7)$ & $17.4(14.1-19.1)$ & $35.3(34.4-35.8)$ \\
\hline Dense mode & $\begin{array}{l}\text { MW-III/ } \\
\text { SAMW }\end{array}$ & $189(123-255)$ & $132(69-177)$ & $26.55(26.5-26.6)$ & $0.7(0.4-0.9)$ & $12.9(10.9-14.6)$ & $35.4(34.9-35.7)$ \\
\hline \multicolumn{8}{|c|}{ South Atlantic subtropical gyre } \\
\hline Light mode core & MW-I & $245(94-321)$ & $137(84-198)$ & $26.51(26.4-26.6)$ & $0.9(0.7-1.2)$ & $13.7(11.2-15.0)$ & $35.5(35.0-35.8)$ \\
\hline \multicolumn{8}{|c|}{ South Indian subtropical gyre } \\
\hline Light mode & MW-I & $174(103-208)$ & $135(66-183)$ & $25.94(25.9-26.0)$ & $1.2(1.0-1.5)$ & $17.0(16.5-17.8)$ & $35.7(35.7-36.0)$ \\
\hline \multicolumn{8}{|c|}{ Permanent pycnoclines } \\
\hline \multicolumn{8}{|c|}{ North Pacific subtropical gyre } \\
\hline Light mode & West & $397(263-546)$ & $283(199-360)$ & $25.82(25.8-25.9)$ & $5.0(4.8-5.3)$ & $13.7(13.0-14.2)$ & $34.6(34.6-34.7)$ \\
\hline Dense mode & Northeast & $322(223-478)$ & $285(158-408)$ & $26.52(26.5-26.6)$ & $2.3(2.1-2.6)$ & $7.7(6.5-8.6)$ & $34.1(34.0-34.3)$ \\
\hline \multicolumn{8}{|c|}{ North Atlantic subtropical gyre } \\
\hline Light mode & West & $722(322-871)$ & $439(293-520)$ & $27.11(27.0-27.2)$ & $2.3(2.0-2.5)$ & $10.9(9.9-12.1)$ & $35.6(35.5-35.8)$ \\
\hline Dense mode & Northeast & $703(447-829)$ & $382(259-483)$ & $27.38(27.3-27.4)$ & $1.3(1.0-1.5)$ & $9.6(7.1-11.7)$ & $35.7(35.2-36.1)$ \\
\hline \multicolumn{8}{|c|}{ South Pacific subtropical gyre } \\
\hline Light mode & East & $290(189-371)$ & $187(143-219)$ & $26.08(26.0-26.1)$ & $5.3(5.1-5.6)$ & $13.8(11.9-16.3)$ & $35.0(34.5-35.6)$ \\
\hline Dense mode & Southwest & $298(203-384)$ & $120(53-576)$ & $26.68(26.6-26.7)$ & $1.3(1.1-1.6)$ & $11.3(9.6-12.3)$ & $35.1(34.8-35.3)$ \\
\hline \multicolumn{8}{|c|}{ South Atlantic subtropical gyre } \\
\hline Light mode & West & $379(207-501)$ & $203(93-332)$ & $26.79(26.7-26.9)$ & $1.7(1.5-2.0)$ & $9.7(8.1-11.1)$ & $34.9(34.6-35.2)$ \\
\hline \multicolumn{8}{|c|}{ South Indian subtropical gyre } \\
\hline Light mode & West & $292(201-340)$ & $144(95-221)$ & $26.18(26.1-26.2)$ & $2.7(2.5-3.0)$ & $15.7(15.3-16.1)$ & $35.6(35.6-35.7)$ \\
\hline
\end{tabular}

Note. Properties are given for each of the mode water and permanent pycnocline modes identified Figure 5 . The mode water types and permanent pycnocline locations are indicated (MW-I, MW-II, and MW-II hold for mode water of types I, II, and III). Properties indicated as mean (min-max) are depth, thickness, potential density $\sigma_{0}$, stratification $N^{2}$, potential temperature $\theta$, and practical salinity $S$. OAC-P $=$ Objective Algorithm for the Characterization of the Permanent Pycnocline; SPMW = Subpolar Mode Water; SAMW = Subantarctic Mode Water.

it is. However, this does not imply a clear dynamic connection between the eastern and western bowls of permanent pycnocline depths. On the other hand, the mode water probability density function contours show a less pronounced relationship between mode water density and stratification. Nonetheless, we will note that when two modes exists, the one located on the poleward flank of the gyre has a much smaller stratification difference between its permanent pycnocline and mode water than the one located further equatorward.

In all basins, the mode water and permanent pycnocline layers are thus continuously defined throughout the subtropical gyre. Indeed, Figure 2 shows that the meridional extension of the mode water and permanent pycnocline layers is from the Western Boundary Current extensions and Arctic and SubAntarctic Fronts on the poleward edge, to the Subtropical Fronts or Equatorial Currents on the equatorward edge of the gyres. Despite the fact that clear regional patterns emerge in the eastern and western parts of the gyres (see 
above), the subtropical stratification pattern of a pycnostad overlying a permanent pycnocline thus exists continuously throughout the gyre.

\section{Discussion}

Following previous work in the North Atlantic by Feucher et al. (2016) and procedures by Feucher (2016), we applied the OAC-P method to the global Argo data set. For all Argo profiles, we identified the depth of a permanent pycnostad overlying a permanent pycnocline for the midlatitudes of all the subtropical gyres of the World Ocean. We then derived their thickness and thermohaline properties and computed their 2000-2015 climatological maps. These maps characterize the properties of the main stratification elements of the midlatitude warm water sphere at the beginning of the 21 st century.

As illustrated Figure 1, the OAC-P algorithm is able to handle the stratification specificities of each subtropical gyres. The algorithm can still be improved tough. In particular, we used a simple temperature threshold method to determine the thickness of the mode water layer to be able to compare our results with previous work (successfully). This may not be totally consistent with our stratification pattern approach and could be refined using a stratification threshold or a parametric pattern model. This later solution is the one used to determine the thickness of the upper and lower permanent pycnocline layers. For the permanent pycnocline, the parametric pattern model is the normal distribution (Feucher et al., 2016). This model was chosen to bridge geometric with physical understanding of the layer thickness. Indeed, if the vertical transition between a warm and a cold water reservoir is primarily driven by diapycnal diffusion, any solution to the diffusion equation could be used to modelize the boundary layer between the reservoirs. The complementary error function is such a solution, and its derivative, the Gaussian distribution, is thus an appropriate parametric model for the pycnocline layer thickness. This approach could be applied to the mode water core as well.

Tsubouchi et al. (2016) have shown the difficulty to describe objectively all subtropical mode waters of type I using temperature and a "thermostad" approach. Using an alternative and more general methodology (based on density), we have shown in this study that most of subtropical mode waters can be identified using their signature into the generic subtropical stratification pattern of a pycnostad overlying a pycnocline. However, our methodology has also some limitations. For instance, the small South Pacific Subtropical Mode Water of Type I (Tsubouchi et al., 2007) is correctly identified locally by its thermohaline properties (Figure 3 shows at the known location of the mode water of type I an appropriate density of $26 \mathrm{~kg} / \mathrm{m}^{3}$, potential temperature of $17^{\circ} \mathrm{C}$, and practical salinity of 35.5). However, it does not stand out as a regional extrema in the climatological thickness map and is rather diluted within a large-scale meridional gradient (Figure $2 \mathrm{~b}$ ). Moreover, because we computed a climatology, we could only map stationary stratification features. Hence, it is impossible to capture "transient" features, such as, for instance, the mode water of type II found in the Southeast Atlantic within the intermittent Alghulas leakage region (Donners et al., 2005).

One must note that we excluded the Southeast Indian Ocean from our description of the subtropical mode water and permanent pycnocline stack. This choice was motivated by the fact that the observed eastern SIO variety of mode water is not locally ventilated in winter. In this region, the observed mode water is a light flavor of Subantarctic Mode Water, also named Southeast Indian SAMWs (McCartney, 1982). This mode water is formed north of the Subantarctic Front in the southeast Indian Ocean and then spreads northwestward and ventilate the deep Indian Ocean subtropical gyre (Cerovecki et al., 2013; Sallée et al., 2006). But, as this ventilation occurs in particularly deep layers (about $450 \mathrm{~m}$ for the mode water and $900 \mathrm{~m}$ for the permanent pycnocline at $35^{\circ} \mathrm{S}, 85^{\circ} \mathrm{W}$ ), owing to its origin in the very deep mixed layer along the Antarctic Circumpolar Current, the permanent pycnocline and the seasonal pycnocline remain distinct features in winter at midlatitudes (e.g., $35^{\circ} \mathrm{S}$ ). This particularity is also found in the Southeast Pacific between $40^{\circ} \mathrm{S}$ and $50^{\circ} \mathrm{S}$. This ventilation pattern does not fit our definition of a pycnostad overlying a permanent pycnocline and trapped temporarily below the seasonal pycnocline and is different from the eastern mode waters of type III observed in the North Hemisphere (also originating from convection along the Sub-Arctic Front) that remain ventilated by deep mixed layers further south in the gyres. The exclusion of the Southeastern Indian Ocean is clearly a strong limitation of our study. However, owing to the specific nature of SAMW, the description of its associated stack of mode water and permanent pycnocline and how it contributes to the shape of the warm water sphere in the Eastern Indian Ocean is left to a future study. 

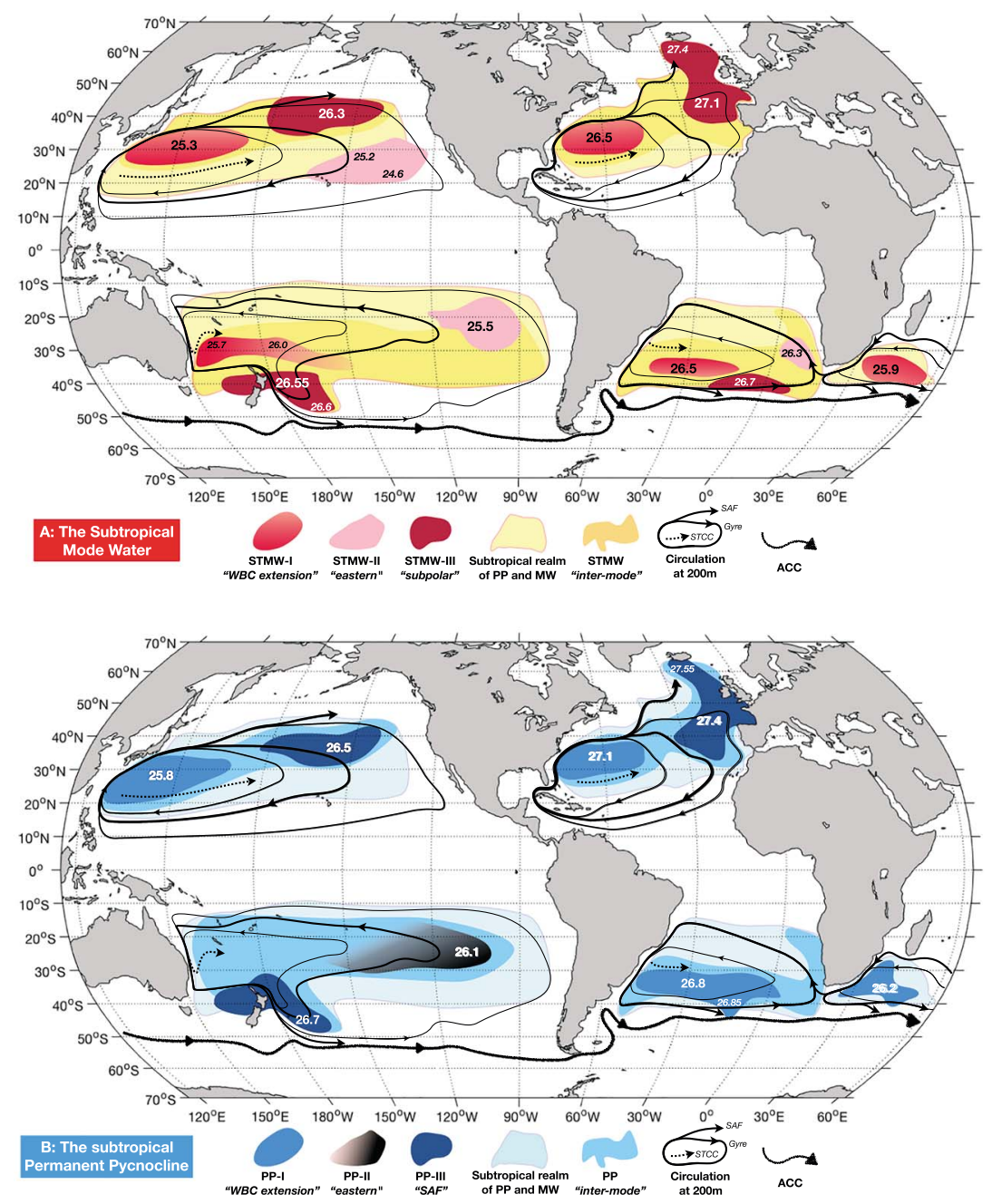

Figure 6. Schematic representation of subtropical mode waters (a) and permanent pycnocline (b) distributions, with typical potential densities and subtropical gyre and Antarctic Circumpolar Current circulation at 200-m depth. The mode water and permanent pycnocline color codes are given in the legends of each schematics (for mode waters we used the same color code as ; Hanawa \& Talley, 2001). The subtropical circulation is from the Argo-based geopotential height at $200 \mathrm{~m}$ derived from Ollitrault and Colin de Verdière (2014). Dash arrows indicate the main surface-trapped subtropical countercurrents (Ganachaud et al., 2014; Kobashi \& Kubokawa, 2012; Memery et al., 2000; Ullman et al., 2007). Acronyms: ACC = Antarctic Circumpolar Current; STCC = subtropical countercurrent; STMW = subtropical mode water; $\mathrm{PP}=$ permanent pycnocline; $\mathrm{MW}=$ mode water.

Subtropical mode waters are classically understood as volumetric modes in the temperature and salinity space. Here, we have shown that the subtropical stratification pattern of a mode water pycnostad overlying a permanent pycnocline exists continuously throughout the gyre. One straightforward consequence of this result is that subtropical mode waters can be seen as modes in the density and stratification dimensions of the subtropical pycnostad continuous surface. This is also true for the permanent pycnocline, which cannot easily be defined as a minima in a volumetric census in the temperature and salinity space: the permanent pycnocline is much easier identified in the density and stratification dimensions of the pycnocline continuous surface (Figure 5). This result leads to a more objective identification of the mode waters and permanent pycnoclines. They can simply be identified with a probability density function contour from which average and range of properties can be computed. This is what we have done and results are given for reference in Table 1.

To put these results into perspective, Figure 6 proposes a schematic for the density and stratification modes distribution of the mode water and permanent pycnocline. The mode water schematic can be seen as an update to Hanawa and Talley (2001) Plate 5.4.3. The main changes are the following. First, the mode water 
type III, associated with the Sub-Arctic and Sub-Antarctic Fronts, is limited in our analysis to the varieties overlying a permanent pycnocline on the equatorward flank of these fronts, roughly over regions where the wind-stress curl remains negative. That is why the subtropical realm in our schematic does not overlap with some part of the cyclonic subpolar gyres regions, contrary to the Hanawa and Talley (2001) representation. The second main update is that we included the STMW "intermode" flavors, that is, the mode waters connecting the modes found in the $\sigma_{0} / N^{2}$ diagrams (Figure 5). These mode waters provide a continuous link between the western and eastern mode water types and occupy a significant fraction of the subtropical gyre surfaces. This furthermore allows to clearly encounter for mode waters formed along the Sub-Antarctic Front poleward bifurcation and referred to as Central Mode Waters in the North Pacific (Oka \& Qiu, 2012) and Central, or $11-12^{\circ} \mathrm{C}$, Waters in the North Atlantic (Hanawa \& Talley, 2001). The third update is the more detailed representation of the subtropical circulation streamlines based on the mean geopotential height at $200 \mathrm{~m}$, as derived by Ollitrault and Colin de Verdière (2014) with Argo data only. We chose to highlight the streamlines relevant to mode waters: the largest anticyclonic closed streamline, the largest streamline enclosing the mode water of type I, and an intermediate streamline passing through the center of the gyres, between the western and eastern thickest features. We furthermore indicated an open streamline to represent the poleward bifurcation of the Sub-Arctic and Sub-Antarctic Fronts, the limit of the subtropical gyre and mode water of type III. Another new and relevant circulation feature is the explicit representation of subtropical counter currents (STCCs, dashed arrows). As reviewed by Kobashi and Xie (2012) in the North Pacific and more recently suggested by Capet et al. (2016) in the North Atlantic, the meridional potential vorticity gradient associated with the equatorward edge of the mode water of type I plays a crucial role in the STCC formation. The STCC can thus be seen as the equatorward limit of the mode water of type I extent.

Using a similar approach to mode waters, Figure $6 \mathrm{~b}$ is an attempt at a representative schematic for the permanent pycnocline distribution. The schematic highlights the western and eastern regions of deep permanent pycnoclines that also correspond to thick mode waters and mostly follow an isopycnal surface (density values are indicated on the schematic as well). We found that regions of deep subtropical permanent pycnoclines are colocated with thick mode waters (Figure 2). This can result from a simple heuristic argumentation stating that for a given buoyancy flux, the depth of the ventilated ocean (i.e., the permanent pycnocline) will be deeper for regions where the upper stratification is smaller (i.e., thick mode water). This, of course, can explain why these two variables are correlated but does not point toward any of the possible mechanisms driving their distribution in space.

Furthermore, we found that the pycnocline is shallower in the center of the subtropical gyres. Where this shallower pycnocline is observed, it is flanked by two regions of deeper permanent pycnocline, which creates a remarkable double-bowl pattern at the basin scale. This can be seen Figure $6 \mathrm{~b}$ where they are two distinct "modes" of permanent pycnocline, coined PP-I, PP-II, or PP-III by analogy to the mode water varieties. The thermohaline properties of the pycnocline furthermore indicate that each of the deep centers are associated with a mode in the density and stratification plan.

Thus, it appears that the subtropical gyres are characterized by two regions where (i) the pycnocline core is deep and nearly follows an isopycnal surface and (ii) the pycnocline core is shallow and crosses several isopycnal surfaces. It is tempting to generalize this result to all subtropical gyres, but it is clearly seen only for the North Atlantic and North Pacific subtropical gyres, less so for the South Pacific, while other gyres have specificities that probably limit this general pattern to take place. To our knowledge, it is the first time that such a structure is described. We believe this result to manifest itself because of our methodology, which is based on stratification patterns rather than on isopycnal depths. The literature with regard to the thermocline ventilation is large, as this is a historical problem in oceanography (Pedlosky, 2006). To provide a rational physical explanation for this double-bowl pattern is beyond the scope of this descriptive study and will be addressed elsewhere.

Our global description of the warm water sphere stratification at midlatitudes highlights that the North Atlantic Ocean stands out as an extreme case compared to the other four subtropical gyres, as already pointed out by Tsubouchi et al. (2016) for mode water of type I only. The North Atlantic shows a deeper, thicker, and less stratified permanent pycnocline and surface mode water. An explanation for this observation could be that the North Atlantic circulation is the only one where a strong overturning circulation adds to the wind-driven circulation, leading to a Gulf Stream transport at least twice as intense as the other boundary 
current system (Kwon et al., 2010; Stommel, 1957; Tsubouchi et al., 2016). This is consistent with the North Atlantic permanent pycnocline being nearly twice deeper than in other gyres.

\section{Conclusion}

Using Argo data and a new diagnostic method, we presented a 2000-2015 climatology of the warm water sphere stratification at midlatitudes. This climatology, schematically represented in a more dynamical context in Figure 6, highlighted the following key results:

1. In each basins, the subtropical stratification pattern of a mode water pycnostad overlying a permanent pycnocline exists continuously throughout the gyre.

2. The subtropical permanent pycnocline shows two deep centers colocated with thick mode waters (either subtropical and/or subpolar mode waters) in the NATL, NPAC, and SPAC.

3. The pycnocline is shallower in the center of the subtropical gyres, which creates a double-bowl pattern at the basin scale that significantly differs from the classic wind-driven west equatorward deepening of isopycnal surface depths.

4. The approximation of the permanent pycnocline depth by an isopycnal surface is only possible in limited regions, that is, in the western boundary current recirculation and eastern flow regions on the equatorward flank of Sub-Antarctic Front.

5. The singularity of the North Atlantic subtropical gyre stratification is shown, with the deepest and thickest mode water and permanent pycnocline observed.

It seems to us that the pycnocline is generally thought of as a continuous surface, mostly isopycnic, bounding the subtropical gyre, whereas mode waters are restricted to clearly bounded bulks of water. The conclusion of this study is that, using in-situ observations, we can show that there exist as many permanent pycnocline flavors as their overlying mode waters. On one hand, we provided a continuous description of the mode water layer (connecting all mode water types I, II, and III), and on the other hand, we provided a regional description of the permanent pycnocline that introduces clearly different structures throughout the gyres. The climatological data set presented in this study is freely available (https://doi.org/10.17882/56503; Feucher et al., 2018). We hope that this data set will lead to further studies of the large-scale structure of the pycnocline and of its ventilation processes.

Acknowledgments

Argo data were collected and made freely available by the International Argo Program and the national programs that contribute to it (http://www.argo.ucsd.edu, http://argo.jcommops.org). The Argo Program is part of the Global Ocean Observing System. C. Feucher and G. Maze were supported by IFREMER (Institut Français de Recherche pour l'Exploitation de la Mer), and $\mathrm{H}$. Mercier was supported by the French CNRS (Centre National de la Recherche Scientifique). This study was supported by the CNRS-LEFE

[Les Enveloppes Fluides et l'Environnement, project SOMOVAR. Authors wish to thank Alain Colin de Verdière for sharing ANDRO-derived velocity fields and two anonymous reviewers for their constructive comments that helped improved this manuscript.

\section{References}

Argo (2016). https://doi.org/10.17882/42182

Capet, X., Roullet, G., Klein, P., \& Maze, G. (2016). Intensification of upper ocean submesoscale turbulence through Charney Baroclinic instability. Journal of Physical Oceanography, 46(11), 3365-3384. https://doi.org/10.1029/2011JC007409

Carton, J. A., Cunningham, S. A., Frajka-Williams, E., Kwon, Y. O., Marshall, D. P., \& Msadek, R (2014). The Atlantic overturning circulation: More evidence of variability and links to climate. Bulletin of the American Meteorological Society, 95(8), ES163-ES166.

Carval, T., Keeley, B., Takatsuki, Y., Yoshida, T., Loch, S., Schmid, C., et al. (2013). Argo user's manual V3.03. (Tech. rep.). https://doi.org/ $10.13155 / 26387$

Cerovecki, I., Talley, L. D., Mazloff, M. R., \& Maze, G. (2013). Subantarctic mode water formation, destruction, and export in the eddy-permitting southern ocean state estimate. Journal of Physical Oceanography, 43(7), 1485-1511.

Cessi, P. (2007). Regimes of thermocline scaling: The interaction of wind stress and surface buoyancy. Journal of Physical Oceanography, 37(8), 2009-2021.

Cessi, P., \& Fantini, M. (2004). The eddy-driven thermocline. Journal of Physical Oceanography, 34(12), $2642-2658$.

Cheng, L., Trenberth, K. E., Fasullo, J., Boyer, T., Abraham, J., \& Zhu, J. (2017). Improved estimates of ocean heat content from 1960 to 2015. Science Advances, 3(3), e1601545.

de Boyer Montégut, C., Madec, G., Fischer, A. S., Lazar, A., \& Iudicone, D. (2004). Mixed layer depth over the global ocean: An examination of profile data and a profile-based climatology. Journal of Geophysical Research, 109, C12003. https://doi.org/10.1029/2004JC002378

Dong, S., Hautala, S. L., \& Kelly, K. A. (2007). Interannual variations in upper-ocean heat content and heat transport convergence in the western North Atlantic. Journal of Physical Oceanography, 37(11), 2682-2697.

Dong, S., \& Kelly, K. A. (2004). Heat budget in the Gulf Stream region: The importance of heat storage and advection. Journal of Physical Oceanography, 34(5), 1214-1231.

Donners, J., Drijfhout, S. S., \& Hazeleger, W. (2005). Water mass transformation and subduction in the South Atlantic. Journal of Physical Oceanography, 35(10), 1841-1860.

Feucher, C. (2016). Stratification structure in subtropical gyres and its decadal variability in the North Atlantic Ocean (Ph.D. thesis), Université de Bretagne Occidentale.

Feucher, C., Maze, G., \& Mercier, H. (2016). Mean structure of the North Atlantic subtropical permanent pycnocline from in situ observations, vol. 33, pp. 1285-1308. https://doi.org/10.1175/JTECH-D-15-0192.1

Feucher, C., Maze, G., \& Mercier, H. (2018). 2000-2015 climatology of the World Ocean subtropical mode water and permanent pycnocline properties, SEANOE, https://doi.org/10.17882/56503

Forget, G., Maze, G., Buckley, M., \& Marshall, J. (2011). Estimated seasonal cycle of north atlantic eighteen degree water volume. Journal of Physical Oceanography, 41(2), 269-286. 
Ganachaud, A., Cravatte, S., Melet, A., Schiller, A., Holbrook, N. J., Sloyan, B. M., et al. (2014). The southwest pacific ocean circulation and climate experiment (spice). Journal of Geophysical Research: Oceans, 119, 7660-7686. https://doi.org/10.1002/2013JC009678

Häkkinen, S., Rhines, P. B., \& Worthen, D. L. (2015). Heat content variability in the North Atlantic Ocean in ocean reanalyses. Geophysical Research Letters, 42, 2901-2909. https://doi.org/10.1002/2015GL063299

Häkkinen, S., Rhines, P. B., \& Worthen, D. L. (2016). Warming of the Global Ocean: Spatial structure and water-mass trends. Journal of Climate, 29(13), 4949-4963. https://doi.org/10.1175/JCLI-D-15-0607.1

Hanawa, K., \& Talley, L. D. (2001). Ocean circulation and climate: Observing and modelling the global ocean. In G. Siedler, J. Church, \& J. Gould (Eds.), chap. Mode waters (Vol. 77, pp. 373-386). San Fransisco CA, USA: Academic Press.

Hautala, S. L., \& Roemmich, D. H. (1998). Subtropical mode water in the northeast Pacific basin. Journal of Geophysical Research, 103(C6), $13,055-13,066$.

Helm, K. P., Bindoff, N. L., \& Church, J. A. (2011). Observed decreases in oxygen content of the global ocean. Geophysical Research Letters, 38, L23602. https://doi.org/10.1029/2011GL049513

Huang, R. (1990). On the three-dimensional structure of the wind-driven circulation in the North Atlantic. Dynamics of Atmospheres and Oceans, 15(1-2), 117-159.

Keffer, T. (1985). The ventilation of the world's oceans: Maps of the potential vorticity field. Journal of Physical Oceanography, 15(5), 509-523.

Kelly, K. A., \& Dong, S. (2013). The contributions of atmosphere and ocean to North Atlantic Subtropical mode water volume anomalies. Deep Sea Research, II(91), 111-127. https://doi.org/10.1016/j.dsr2.2013.02.020

Kelly, K. A., Thompson, L., \& Lyman, J. (2014). The coherence and impact of meridional heat transport anomalies in the Atlantic ocean inferred from observations. Journal of Climate, 27(4), 1469-1487. https://doi.org/10.1175/JCLI-D-12-00131.1

Kobashi, F., \& Kubokawa, A. (2012). Review on north pacific subtropical countercurrents and subtropical fronts: Role of mode waters in ocean circulation and climate. Journal of Oceanography, 68(1), 21-43.

Kobashi, F., \& Xie, S.-P. (2012). Interannual variability of the North Pacific subtropical countercurrent: Role of local ocean-atmosphere interaction. Journal of Oceanography, 68(1), 113-126.

Kwon, Y.-O. (2003). Observation of general circulation and water mass variability in the North Atlantic Subtropical Mode Water region (PhD thesis), University of Washington.

Kwon, Y.-O., Alexander, M. A., Bond, N. A., Frankignoul, C., Nakamura, H., Qiu, B., \& Thompson, L. (2010). Role of the Gulf Stream and Kurushio-Oyashio systems in large-scale atmosphere-ocean interaction: A review. Journal of Climate, 23, 3249-3281. https://doi.org/ 10.1175/2010JCLI3343.1

Levitus, S., Antonov, J. I., Boyer, T. P., Baranova, O. K., Garcia, H. E., Locarnini, R. A., et al. (2012). World ocean heat content and thermosteric sea level change (0-2000 m), 1955-2010. Geophysical Research Letters, 39, L10603. https://doi.org/10.1029/2012GL051106 Luyten, J. R., Pedlovsky, J., \& Stommel, H. (1983). The ventilated thermocline. Journal of Physical Oceanography, 13(2), 292-309.

McCartney, M. (1982). The subtropical recirculation of mode waters. Journal of Marine Research, 40, 427-464.

McDowell, S., Rhines, P., \& Keffer, T. (1982). North Atlantic potential vorticity and its relation to the general circulation. Journal of Physical Oceanography, 12(12), 1417-1436.

Memery, L., Arhan, M., Alvarez-Salgado, X. A., Messias, M. J., Mercier, H., Castro, C. G., \& Rios, A. F. (2000). The water masses along the Western boundary of the South and equatorial Atlantic. Progress In Oceanography, 47(1), 69-98.

Oka, E., \& Qiu, B. (2012). Progress of north pacific mode water research in the past decade. Journal of Oceanography, 68(1), 5-20.

Ollitrault, M., \& Colin de Verdière, A. (2014). The ocean general circulation near 1000-m depth. Journal of Physical Oceanography, 44(1), 384-409.

Pedlosky, J. (2006). A history of thermocline theory. In M. Jochum \& R. Murtugudde (Eds.), Physical Oceanography (pp. 139-152). New York, NY: Springer.

Provost, C., Escoffier, C., Maamaatuaiahutapu, K., Kartavtseff, A., \& Garçon, V. (1999). Subtropical mode waters in the South Atlantic Ocean. Journal of Geophysical Research, 104(C9), 21,033-21,050.

Radko, T., \& Marshall, J. (2004). Eddy-induced diapycnal fluxes and their role in the maintenance of the thermocline. Journal of physical oceanography, 34(2), 372-383.

Riser, S. C., Freeland, H. J., Roemmich, D., Wijffels, S., Troisi, A., Belbeoch, M., et al. (2016). Fifteen years of ocean observations with the global Argo array. Nature Climate Change, 6(2), 145-153. https://doi.org/10.1038/nclimate2872

Roemmich, D., Church, J., Gilson, J., Monselesan, D., Sutton, P., \& Wijffels, S. (2015). Unabated planetary warming and its ocean structure since 2006. Nature Climate Change, 5(3), 240-245.

Sallée, J.-B., Wienders, N., Speer, K., \& Morrow, R. (2006). Formation of subantarctic mode water in the southeastern Indian Ocean. Ocean Dynamics, 56(5), 525-542.

Siedler, G., Kuhl, A., \& Zenk, W. (1987). The Madeira mode water. Journal of Physical Oceanography, 17(10), 1561-1570.

Speer, K., \& Forget, G. (2013). Global distribution and formation of mode water. In G. Siedler et al. (Eds.), Ocean circulation and climate: A 21st century perspective (Vol. 103, pp. 211-226). New York: Academic Press.

Stommel, H. (1957). A survey of ocean current theory. Deep Sea Research, 4, 149-184. https://doi.org/10.1016/0146-6313(56)90048-X

Sugimoto, S., Hanawa, K., Watanabe, T., Suga, T., \& Xie, S.-P. (2017). Enhanced warming of the subtropical mode water in the North Pacific and North Atlantic. Nature Climate Change, 7, 656-658. https://doi.org/10.1038/nclimate3371

Talley, L. D. (1985). Ventilation of the subtropical North Pacific: The shallow salinity minimum. Journal of Physical Oceanography, 15(6), 633-649.

Talley, L. D. (1999). Some aspects of ocean heat transport by the shallow, intermediate and deep overturning Circulations. In P. U. Clark, R. S. Webb, \& L. D. Keigwin (Eds.), Mechanisms of global climate change at millennial time scales (Vol. 112, pp. 1-22). Washington, DC: American Geophysical Union. https://doi.org/10.1029/GM112p0001

Talley, L. D., Feely, R. A., Sloyan, B. M., Wanninkhof, R., Baringer, M. O., Bullister, J. L., et al. (2016). Changes in ocean heat, carbon content, and ventilation: A review of the first decade of GO-SHIP global repeat hydrography. Annual Review of Marine Science, 8(1), 185-215.

Tsubouchi, T., Suga, T., \& Hanawa, K. (2007). Three types of South Pacific subtropical mode waters: Their relation to the large-scale circulation of the South Pacific subtropical gyre and their temporal variability. Journal of Physical Oceanography, 37(10), 2478-2490.

Tsubouchi, T., Suga, T., \& Hanawa, K. (2016). Comparison study of subtropical mode waters in the world ocean. Frontiers in Marine Science, 3, 270. https://doi.org/10.3389/fmars.2016.00270

Tsuchiya, M., Talley, L., \& McCartney, M. (1994). Water-mass distributions in the Western South Atlantic: A section from South Georgia island (54s) Northward across the equator. Journal of Marine Research, 52(1), 55-81.

Ullman, D. S., Cornillon, P. C., \& Shan, Z. (2007). On the characteristics of subtropical fronts in the north atlantic. Journal of Geophysical Research, 112, C01010. https://doi.org/10.1029/2006JC003601 
Vallis, G. K. (2006). Atmospheric and oceanic fluid dynamics: Fundamentals and large-scale circulation. Cambridge: Cambridge University Press.

Wang, G., Cheng, L., Abraham, J., \& Li, C. (2018). Consensuses and discrepancies of basin-scale ocean heat content changes in different ocean analyses. Climate Dynamics, 50(7-8), 2471-2487.

Williams, R. G. (1991). The role of the mixed layer in setting the potential vorticity of the main thermocline. Journal of Physical Oceanography, 21(12), 1803-1814.

Williams, R. G., Roussenov, V., Lozier, M. S., \& Smith, D. (2015). Mechanisms of heat content and thermocline change in the subtropical and subpolar North Atlantic. Journal of Climate, 28, 9803-9815. https://doi.org/10.1175/JCLI-D-15-0097.1

Wu, L., Cai, W., Zhang, L., Nakamura, H., Timmermann, A., Joyce, T., et al. (2012). Enhanced warming over the global subtropical western boundary currents. Nature Climate Change, 2, 161-166. https://doi.org/10.1038/nclimate1353

Yang, H., \& Wang, F. (2009). Revisiting the thermocline depth in the equatorial Pacific. Journal of Climate, 22(13), 3856-3863. https://doi.org/10.1175/2009JCLI2836.1 